\title{
Horses' Senses Involvement in Food Location and Selection
}

\author{
Carla Andreea CULDA ${ }^{a^{*}}$, Alexandru Nicolae STERMIN ${ }^{a}$ \\ ${ }^{a}$ Babeş-Bolyai University Cluj-Napoca, Faculty of Biology and Geology, Department of Taxonomy and \\ Ecology, 5-7 Clinicilor St., 400006, Cluj-Napoca, Romania \\ *corresponding author: culda_carla@yahoo.com
}

Bulletin UASVM Animal Science and Biotechnologies 76(2)/ 2019

Print ISSN 1843-5262; Electronic ISSN 1843-536X

DOI:10.15835/buasvmcn-asb: 0008.19

\begin{abstract}
Senses are an important part of the interaction with the environment. Previous studies has been established that horses use smell and taste in the selection of their food. The involvement of sight in the selection process has not been clarified up to this study. Here, we investigate the involvement of senses in the selection process of food, also the proportion in which, each senses are involved and we evaluate the horses preferences for different colors. Two experiments have been designed and carried out with two racing horses The results obtained have demonstrated that the sight is the main sense in the location of the food, followed by the sense of olfactory organ involved in selecting plants ingested and the sense of taste which contributes less to the selection. There has also been identified a preference of the envolved horses for the pink color used in this experiment.
\end{abstract}

Keywords: taste, smell, seeing, selecting, behaviore, nutrition

\section{Introduction}

The feeding behavior is one of the main parts in the life of horses, because they grant more time to feeding than to any other behavior. Feeding behavior is directly influenced by the type of food and the ability of selecting it. The horses must consume food and also water, to survive (Elia et al., 2010; Fleurance et al., 2016). Beyond the survival, the consumption of the correct quantities of the proper nutritional value in the proportions of food stuff well calculated allows horses to thrive, to grow harmoniously and be productive. The involvement of horses in various activities (exercises, competitions) increases the nutritional requirements and demands therefore more attention in respect of fodder and their proportion (Roberts and Murray, 2013).

Beyond the choice of food, the senses are used by the horses in more types of behavior, such as those that help them to be directed in a suitable area of pasture land, free of dangers. Most of these types of behavior have evolved together with the species and have adapted to the open areas or to those that have been cultivated by man through artificial selection. The knowledge of ingestive behavior is very important to establish a proper diet for a racing horse (Hoffman et al., 2009; Roberts and Murray, 2013; Murray et al., 2015).

In the previous studies it has been established that the smell and taste play an important role in the selection of the diet by horses, making discrimination between the already known food stuffs and the new ones, but they have not clarified the involvement of sight in this selection process (Berg et al., 2016; Hothersall et al., 2010; Jankunis and Whishaw, 2013). Considering the importance of the diet for performance horses we have chosen to study the behavior of feeding of two racing horses.

In this context, our study aims (i) to investigate the involvement of the senses (visual inspection, touch, olfaction and taste) in the selection process 
of food, (ii) to evaluate the proportion in which each senses are involved in selection, and (iii) to evaluate the preferences for different colors related with food selection.

\section{Materials and methods}

The study involved two experiments (Experiments 1 and 2) in which two race horses were used. One of them is Bambi, a mare of 4 years old, Haflinger and weights $320 \mathrm{~kg}$. It is used for trail and endurance riding, dressage, show jumping, vaulting, and therapeutic riding programs especially for children. The other horse is Chance. It is a mare, of race Romanian Sporthorse, 4 years old and weighs $600 \mathrm{~kg}$. This horse only participates in obstacle jumping.

Experiments have been carried out within the framework of an enclosure of 120 acres, on a meadow in Fagaras area (an area in the center of Romania). The survey was carried out in the period from July to September 2017.

1. The evaluation of the senses' involvement in the choice of food. There have been selected bundles with different colored inflorescences of five species of wild plants: Daucus carota (white), Trifolium repens (white), Trifolium pratense (violet) Cichorium intybus (blue) and Tanacetum vulgare (yellow ).

Bundles were placed in plastic boxes, in a vertical position, at a distance of $2 \mathrm{~m}$ from one another. The horses were walked past them, at a distance of $2 \mathrm{~m}$ from the boxes, subsequently to be let to reach at their choice, one of the boxes with inflorescences. The data concerning their behavior were written down in a table like this: 1- if they smelled, tasted and even eat/swallowed that plant and $\mathbf{0}$ - if they presented no interest. The last raw of the table presents the data recorded from both horses. In the other table it was written down the main differences between the two horses involved in our study in point of their preferences.

Once they have chosen their food smelt and tasted it, the horses may decide to chew and to swallow or may at any time during this process to change their conviction in connection with the piece of food and to spit it out if it no longer reaches their expectations (Gill et al., 2011). This experimental phase has been carried out over a period of five days, with 6-8 hours/day. The position of the boxes with different species of plants has been changed every time in order to prevent memorization of the position of a certain box or of a plant respectively by the horses involved in the experiment.

\section{Experiment 2 evaluated the pairing of a colored cardboard with a reward ways}

The experiment was divided into two parts and was based on the pairing of a colored cardboard with a few cubes of sugar.

The first part of the experiment consisted in the association of the blue panel with the reward (sugar) within a period of 3 days, 2 times/day. The blue cardboard was placed on the ground with sugar cubes on it. The pairing process took place through the presentation of the blue panel for 10 seconds, during which time the horses have analyzed/ investigated it, they being given over the blue panel some sugar cubes (of the same hand). After the three days of pairing the blue panel with the reward (sugar) there were other panels used on those 3 days in which the blue panel was not used at all. Once a day for 10 days the horse were presented with 5 colored panels supported by plastic boxes. The positions of the boxes were rotated daily. Sugar cubes were available only behaind the blue panel. They have been positioned at a distance of $1 \mathrm{~m}$ from one another, supported by plastic boxes. Behind the blue panel which involved a reward, there could be found sugar cubes in the box. The arrangement of the colored objects on the meadow has been changed every day, to prevent storing the location of the reward colored panel.

After the completion of the first part of the experiment 2 , there followed a pause of 8 days in which no colored panel were used. The second phase of the experiment 2 consisted in the association of the pink panel with the sugar. The connection process has been carried out over a period of 3 days, using the same method mentioned in the first stage of association with the blue panel. At this stage the working mode is the same as in the first half of the experiment 2 , the difference would be the number of days in which the second stage of the experiment 2 has been carried out (namely it took place during 8 days). It must be mentioned that among the colored panels positioned in a semicircle, on the meadow, there were both the blue and pink panels associated with the reward - the sugar cubes.

Our experiment, based on the brightly colored panels associated with the reward, is similar 
in certain aspects with another experiment conducted by Leblanc (2013), which has assessed the ability of horses to differentiate between the colors and the shades of gray. The differences between our experiment and the experiment conducted by Leblanc (2013) were as follows: they worked in an enclosed space while we worked in an open area, and there was also a difference in the association process of the panel with the reward. Thus, in Leblanc's experiment, they have led the horse to a wooden box, seated on the ground, which was opened at the top where there was a reward (oats) to eat. Then, he repeated the procedure alone (Fig.4). As regards to the manner in which we associated the colored panels (the blue and the pink ones) with the reward it was different. We brought the colored panel in front of the horse; we stretched it toward the horse, so that he could take contact with it and gradually with the sugar cubes. In Leblanc's experiment, in front of the horses there have been placed two boxes, one wearing a colored cardboard, and the other a gray card of the same size. If the horse walked toward the box with the colored cardboard, it was allowed to eat the contents (oats). If the horse walked over to the other (the gray one) it was caught and made to go back. In our experiment, we didn't prevent horses to go to the other panels colored in brown, orange or green) which didn't involve a reward, thus stimulating their spirit of search which didn't make them stop at a certain color or box.

Once the learning process has been completed, in the test phase the horse was to identify the box with the colored cardboard in the middle of boxes arranged in a semicircle bearing the cardboard of various shades of gray. The colored boxes contained oats. In other words, the horse was put in a situation similar to that of a subject who had to answer a multiple-choice question, in which each choice had only one correct answer and this answer was rewarded. Taking into account the number of shades of gray (twenty-seven), there was required to take several steps to ensure that each color was compared with every shade of gray. In our case the horses were put in the situation to choose/identify the cardboard colored in blue, in the first stage, and the pink cardboard in the second stage among the other three colors (brown, orange and green) all the panels being placed in the form of semicircle on the meadow.
The recording and the quantification of the results of the experiment 2 have been carried out like this: each time the horses were filmed, and, according to these records we analyzed the way the horses chose the colors on the lawn, their reaction at the sight of colors, the order in which the colors were selected and how the horses regarded the colored cardboard (the blue and the pink ones) concerned with the reward, apart from the other brightly colored panels which did not hold sweet reward. We noted with a- the first approach of the colored panel, $\mathbf{b}$ - the second cardboard investigated by the horses, then the following panels c, $\mathbf{d}$ and $\mathbf{e}$. In the tables there have been compressed the final results obtained on each day for every horse in the study.

\section{Results and discussion}

1.The experiment 1 concerned the evaluation of the senses involvement in the choice of food.

It has been found that all four plants have been smelt and tasted, but in different proportion. For example, the shamrock reached the highest value (10) followed by the other plants with lower values (Figure 1). Among the four species of plants only three of them were swallowed (wild carrot, chicory and clover) as a result of the choice. As regards the senses, the smell has had the highest rate of involvement (Table 1) followed by taste. The lowest rate concerned the swallowing, which suggested that not everything that had been tasted, reached their expectations and in the end they gave up to their choice. The visual sense also played an important role in the orientation toward a certain species of the plant.

So the three senses occur in the feeding process, the largest rate being held by the olfactory sense, followed by the visual sense and the taste.

At this stage of the experiment, we noticed that the shamrock was truly an favorite food for horses. The shamrock has been smelt, tasted and swallowed by each horse (Fig. 1).

The other plants chosen in this experiment have shown a lower interest to the horses, this thing being somehow expected in a way, because they were not necessarily an essential nutritional food. Daucus carota and Tanacetum vulgare have recorded lower values (for taste- 2, even 3 ) which showed us that they have presented an interest for 


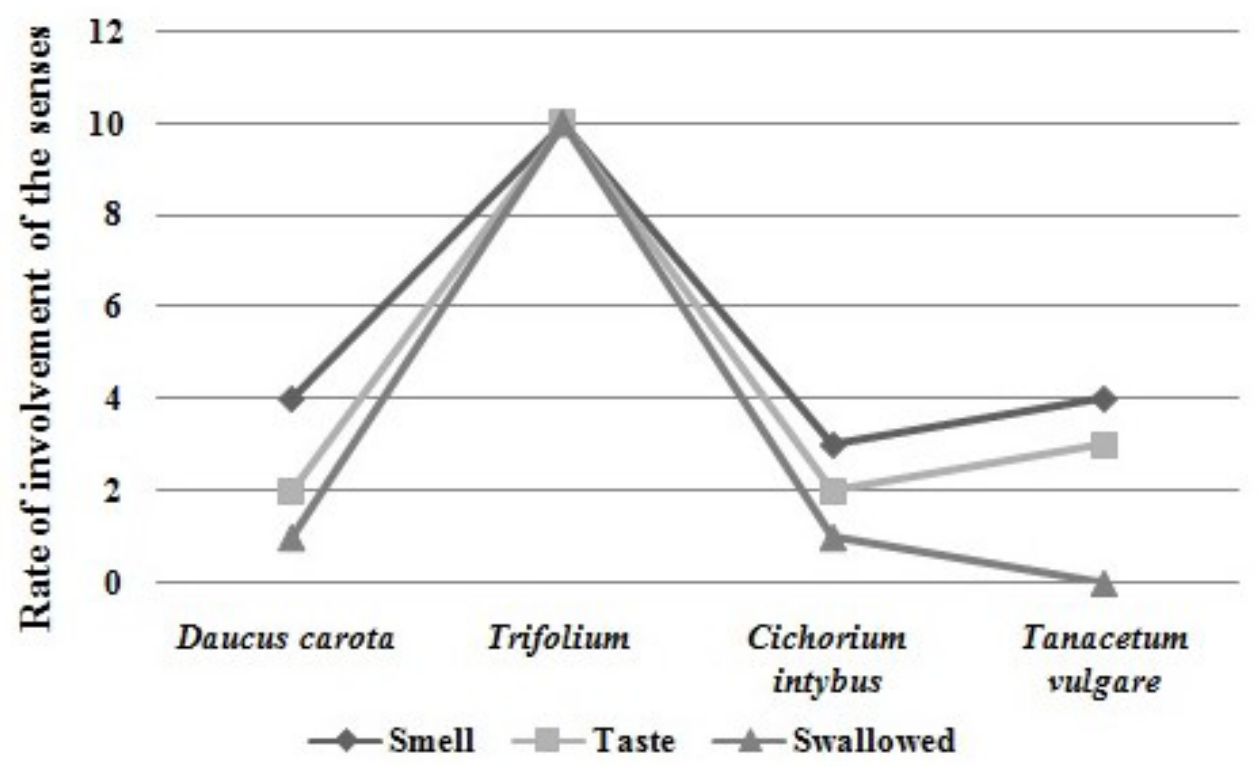

Figure 1. The rate of horses interest for the plants made available.

Table 1. The rate of the horses'behavior to the species of plants placed at disposal

\begin{tabular}{ccccc}
\hline & Daucus carota & Trifolium & Cichorium intybus & Tanacetum vulgare \\
\hline Smell & 4 & 10 & 3 & 4 \\
\hline Taste & 2 & 10 & 2 & 3 \\
\hline Swallowed & 1 & 10 & 1 & 0 \\
\hline
\end{tabular}

Table 2. The choice of plants of differences between the two horses

\begin{tabular}{ccccc}
\hline & Daucus carota & Trifolium & Cichorium intybus & $\begin{array}{c}\text { Tanacetum } \\
\text { vulgare }\end{array}$ \\
\hline Horse 1Bambi & 2 & 5 & 1 & 3 \\
\hline Horse 2 Chance & 2 & 5 & 2 & 1 \\
\hline
\end{tabular}

the horses, but not as significant as in the case of the clover (Table 1).

The horses normally consume their favorite plants in a certain order initially, then as they become fewer the horses chose the other plants which might provide partly or totally the nutritional source they need.

Subsequently we analyzed the trend of exploitation, aiming to the interests of the two horses for the species of plants made available. The result of the analysis shows that both horses, Bambi and Chance, have the same degree of curiosity for the same plants with little variation (Table 2).

And during this experiment we noticed an increased interest of both horses for the species of clover, touching the value 5 . Both horses were interested in wild carrot too. For other species of plants taken in the study, horses have expressed their interests very differently: for example Chance prefers chicory rather than Tanacetum vulgare, while Bambi prefers Tanacetum vulgare rather than chicory (Fig. 2).

2. The experiment 2 evaluated the pairing of a colored cardboard and rewarding ways.

In the first stage of the experiment 2 , it has been found that they didn't stop at a single color, namely the blue color concerned with reward, but they were urged by curiosity toward the other colored cardboard, too. As it can be seen in Table 3 , the annotation $a, b, c, d, e$ is the order in which the colors have been chosen by the horses (for example: $\mathrm{a}=$ the first time, $\mathrm{b}=$ the second time, etc).

Because the fourth time (d) and the fifth time (e) the horses stopped showing a very great 


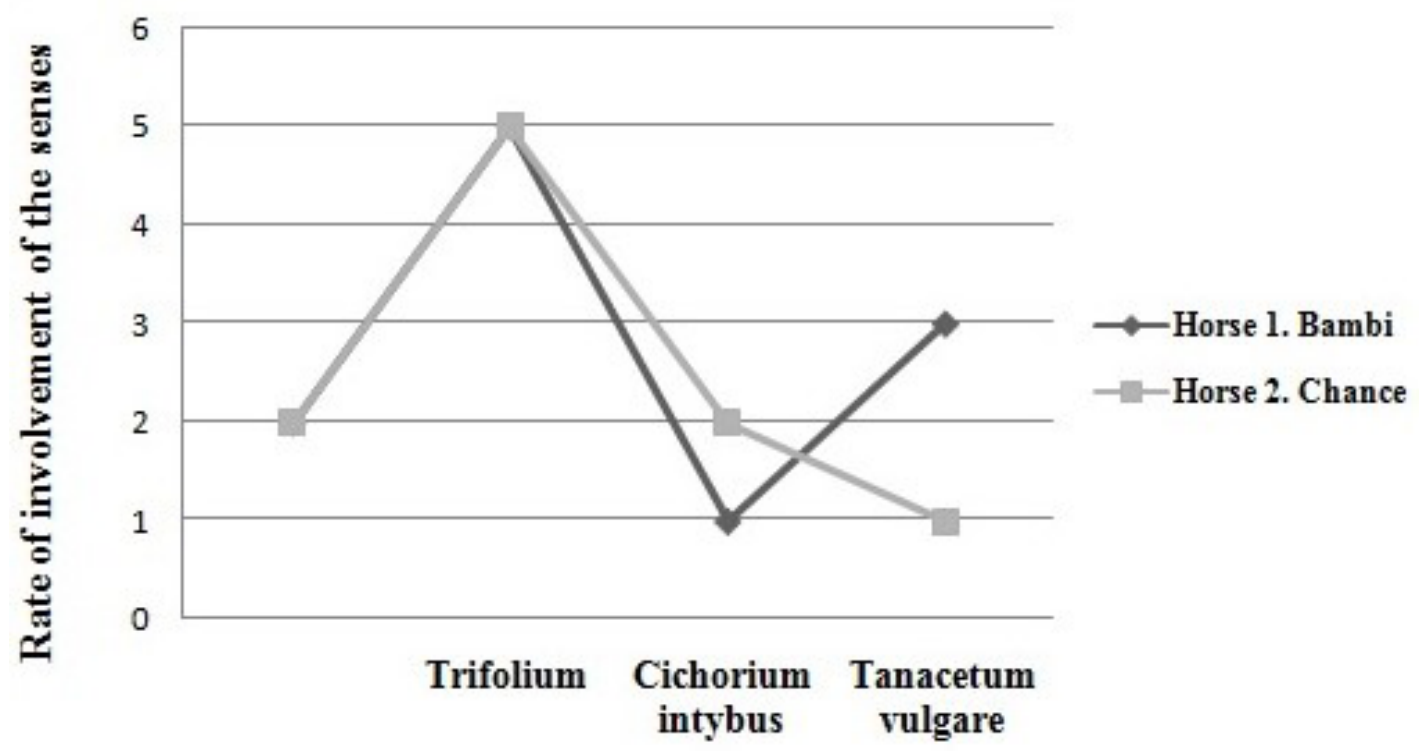

Figure 2. The variation in the choice of plants by horses

Table 3. The horses preferences versus colored cardboard (the blue one with reward)

\begin{tabular}{ccccccccccccccccccccccccccc}
\hline & \multicolumn{1}{c}{ BLUE } & BROWN & \multicolumn{1}{c}{ GREEN } & \multicolumn{1}{c}{ PINK } & \multicolumn{1}{c}{ ORANGE } \\
\hline & a & b & c & d & e & a & b & c & d & e & a & b & c & d & e & a & b & c & d & e & a & b & c & d & e \\
\hline Horse I & 3 & 1 & 5 & - & - & - & 2 & - & 3 & - & 3 & 2 & - & - & 1 & 3 & 1 & - & - & 1 & 1 & 1 & 1 & - & - \\
\hline Horse II & 1 & 2 & 1 & - & - & - & - & - & - & - & - & 2 & - & - & - & 4 & 1 & - & - & - & 1 & - & - & - & - \\
\hline TOTAL & 4 & 3 & 6 & - & - & - & 2 & - & 3 & - & 3 & 4 & - & - & 1 & 7 & 2 & - & - & 1 & 2 & 1 & 1 & - & - \\
\hline
\end{tabular}

Table 4. The main approaches of the horses on colored panels (the blue one with reward)

\begin{tabular}{clll}
\hline & $\mathrm{a}$ & $\mathrm{b}$ & $\mathrm{c}$ \\
\hline BLUE & 4 & 3 & 6 \\
\hline BROWN & 0 & 2 & 0 \\
\hline GREEN & 3 & 4 & 0 \\
\hline PINK & 7 & 2 & 0 \\
\hline ORANGE & 2 & 1 & 1 \\
\hline
\end{tabular}

interest for the colored panels, only the results of the first three approaches have been selected for interpretation. Thus, it can be seen from Table 4 that the horses were interested in the brown, green and pink panels for three times in a row.

In Figure 3 there can be seen that the pink panel was most often chosen first. Then the blue panel got the value of 4 , because the blue one was the rewarded one (with sugar cubes).

In the second part of the experiment we chose among the five colors taken in the study, the pink color to bear the reward (sugar cubes). As it can be seen in Table 5 , the annotation a, b, c, d, e is the order in which the colors were chosen by the horses (for example: $a=$ the first time, $b=$ the second time etc).

In the second part of the experiment the horses had a positive response to the pink color, this one being chosen the first, with the value of 7. It is not sure if the horses associate the pink color with the reward, as in the first part of the experiment the horses chose this color too. By obtaining this information, a number of other questions are to be identified/checked by other more complex studies. 


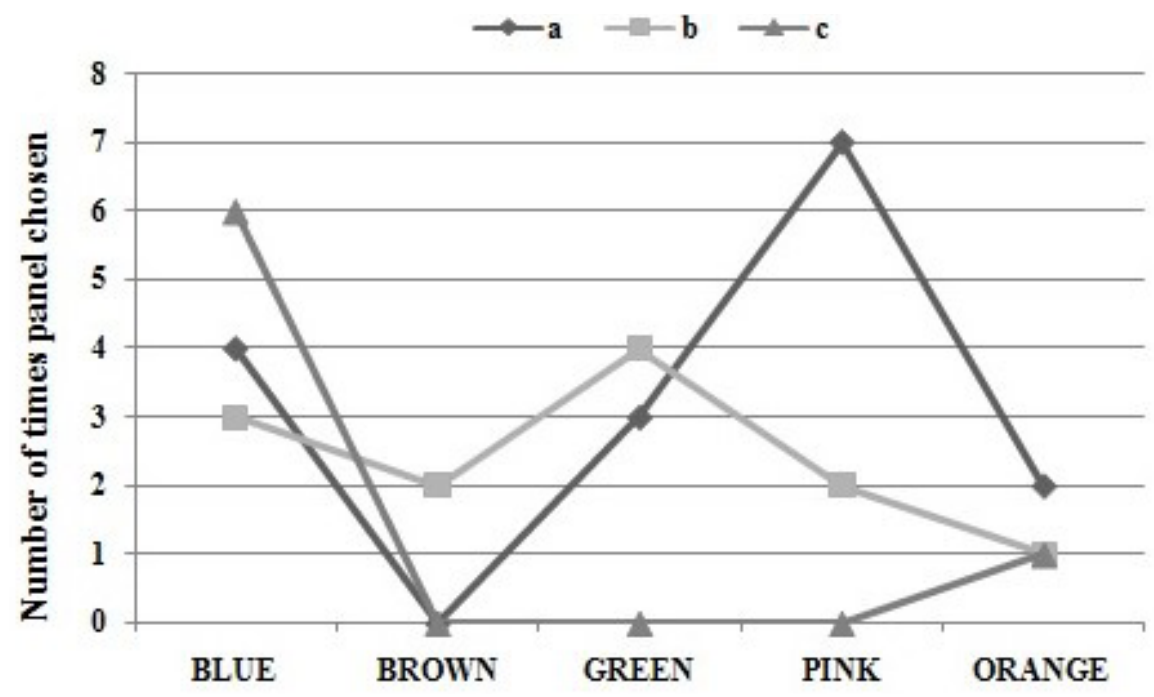

Figure 3. The variation in the preferences of the panels used (the blue one with reward)

Table 5. The horses preferences versus colored cardboard (the pink one with reward)

\begin{tabular}{ccccccccccccccccccccccccccc}
\hline \multicolumn{1}{c}{} & \multicolumn{1}{c|}{ BLUE } & BROWN & \multicolumn{1}{c}{ GREEN } & \multicolumn{1}{c}{ ORINK } & \multicolumn{1}{c}{ ORANGE } \\
\hline & a & b & c & d & e & a & b & c & d & e & a & b & c & d & e & a & b & c & d & e & a & b & c & d & e \\
\hline Horse I & 1 & 1 & 3 & - & - & 2 & 2 & - & - & - & 1 & 3 & - & 1 & - & 4 & - & - & - & 1 & - & 1 & 2 & 1 & - \\
\hline Horse II & - & 1 & 2 & 1 & - & 2 & - & 1 & 1 & - & 1 & 1 & 1 & - & - & 3 & 3 & 1 & - & - & 2 & 3 & - & - & 1 \\
\hline TOTAL & 1 & 2 & 5 & 1 & - & 4 & 2 & 1 & 1 & - & 2 & 4 & 1 & 1 & - & 7 & 3 & 1 & - & 1 & 2 & 4 & 2 & 1 & 1 \\
\hline
\end{tabular}

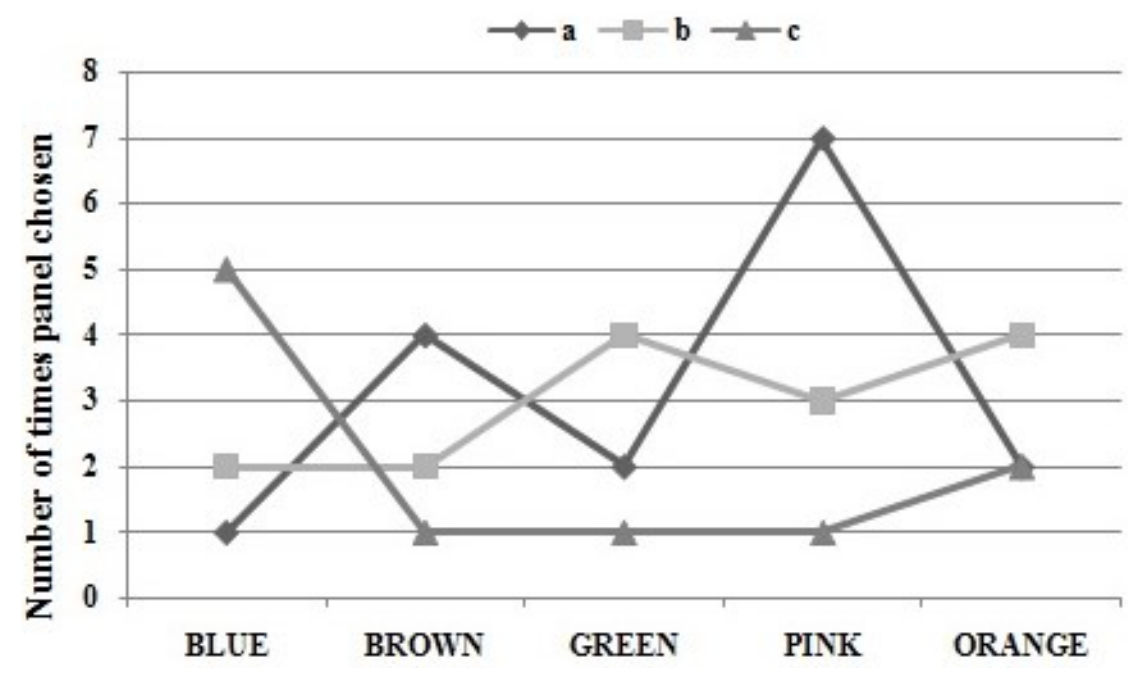

Figure 4. Preferences boards used to reward colored (pink)

Also, we can't say if the horses have a preference for this color or if in this experimental phase they have learned to make the association between color and reward. Usually the behavior of racing horses is slightly ambiguous, having been noted by Waite et al., (2018).
In Figure 4 you can see that the pink color was the first one noticed by horses. It was the color with the reward (sweet sugar cubes). The other colors were chosen on a very variable range.

In the second part of the experiment, in the fourth (d) and the fifth (e) approaches, horses haven't shown interest in the panels. So, only 
Table 6. The main approaches of the horses to the colored cardboard (pink with reward)

\begin{tabular}{cccccc}
\hline & BLUE & BROWN & GREEN & PINK & ORANGE \\
\hline $\mathrm{a}$ & 1 & 4 & 2 & 7 & 2 \\
\hline $\mathrm{b}$ & 2 & 2 & 4 & 3 & 4 \\
\hline $\mathrm{c}$ & 5 & 1 & 1 & 1 & 2 \\
\hline
\end{tabular}

the results of the first three approaches, have been selected for interpretation. Unlike the first part of the experiment, during the first three approaches the horses were attracted to each colored cardboard (the blue cardboard-1; the brown cardboard-4; the green cardboard-2 and the orange cardboard-2), the main interest should be for the pink cardboard with the reward which recorded the value 7 (Table 6).

It could be noticed that they were attracted by the pink color and in the first phase of the experiment 2 recording all the value 7 . Later they also showed some interest in the other colors, among which the blue color was the one with the reward. They knew that behind a color there was a reward. Spirit of the search is informal, but they did not stop at a single color box, but stopped at other color boxes.

This trend of choosing varied colored cardboards used, may be interpreted as a consequence of their evolutionary way of perceiving things. They have learned to move away from certain colors, as they can be dangerous for them (Hall and Cassaday, 2006; Panter et al., 2018). It is well known that the olfactory and gustatory apparatus have a great role in choosing the food for these mammals, while the sense of visual inspection is less important (Berg et al., 2016). The food which will present an unpleasant smell will not be reached by horses. The taste of horses is particularly sensitive.

However, there were made trials related to the involvement of the visual sense in preferential choice of a symbol stirring in the association of the symbols and different needs (Mejdell et al., 2016).

\section{Conclusions}

The results of these experiments brought to light the fact that the sight is the main sense in the location of the food, as the horses firstly noticed the plants' inflorescences. The visual sense is followed by the olfactory sense involved in the selection of plant species reaching the highest value of 21 and finally the sense of taste which indicates the value of the 17, which suggests that it occurs in a smaller proportion in the choice. Among the plants taken in our study the shamrock has been smelt (10), tasted (10), and swallowed (10) by each horse.

In the second experiment we could note the choice of color pink both in the first part and in the second part of the experiment, the value obtained being 7 on both.

The first part of the experiment 2 revealed the horses' tendency to go to the pink color for the first time (value 7). Still we cannot be sure if they exceptionally prefer this color; this was not the color associated with the reward. The blue panel concerned with the reward at this stage recorded a value of 4 , in the case of the first approach to color.

In the second part of the experiment 2 there were positive values as regards the choice of the pink color, by the horses. They directly went to that cardboard (value 7), which, this time, was accompanied by the reward.

\section{Reference}

1. Berg M, Giagos V, Lee C, Brown WY, Cawdell-Smith AJ, Hinch GN (2016). The influence of odour, taste and nutrients on feeding behaviour and food preferences in horses. Applied Animal Behaviour Science, 184, 41-50.

2. Elia JB, Erb HN, Houpt KA (2010). Motivation for hay: Effects of a pelleted diet on behavior and physiology of horses. Physiology \& Behavior, 101, 623-627. Doi:10.1016/j.physbeh.2010.09.010.

3. Fleurance G, Farruggia A, Lanore L, Dumont B (2016). How does stocking rate influence horse behaviour, performances and pasture biodiversity in mesophile grasslands?. Agriculture, Ecosystems and Environment, 231, 255-263. Doi:10.1016/j.agee.2016.06.044.

4. Gill W, Meadows DG, Neel JB (2011). Understanding horse behavior. Agricultural Extension Service Institute of Agriculture, unit 8, grade 12 .

5. Hall CA, Cassaday HJ (2006). An investigation into the effect of floor colour on the behaviour of the horse, Applied Animal Behaviour Science, 99, 301-314. Doi:10.1016/j. applanim.2005.10.018

6. Hoffman CJ, Costa LR, Freeman LM (2009). Survey of feeding practices, supplements use, and knowledge of equine nutrition among a subpopulation of horse owners in New England. Journal of Equine Veterinary Science, 29(10), 719-26. 
7. Hothersall B, Harris P, Sortoft L, Nicol CJ (2010). Discrimination between conspecific odour samples in the horse (Equus caballus). Applied Animal Behaviour Science, 126, 37-44.

8. Jankunis ES, Wishshaw IO (2013). Sucrose Bobs and Quinine Gapes: Horse (Equus caballus) responses to taste support phylogenetic similarity in taste reactivity. Behavioural Brain Research, 256, 284-290.

9. Leblanc MA (2013). The Mind of The Horse. Harvard University Press, (Chapter 8).

10. Mejdell CM, Buvik T, Jorgensen GHM, Boe KE (2016). Horses can learn to use symbols to communicate their preferences. Applied Animal Behaviour Science, 184, 6673.
11. Murray JAMD, Bloxham C, Kulifay J, Stevenson A, Roberts J (2015). Equine Nutrition: A Survey of Perceptions and Practices of Horse Owners Undertaking a Massive Open Online Course in Equine Nutrition. Journal of Equine Veterinary Science, 35, 510-517.

12. Roberts JL, Murray JA (2013). Survey of equine nutrition: perceptions and practices of veterinarians in Georgia, USA. Journal of Equine Veterinary Science, 33, 454-9.

13. Waite K, Heleski C, Ewing M (2018). Quantifying Aggressive Riding Behavior of Youth Barrel Racers and Conflict Behaviors of Their Horses. Journal of Veterinary Behavior. Doi:10.1016/j.jveb.2018.01.002.

14. Panter KE, Welch KD, Gardner DR, Lee ST, Green BT, Pfister JA, Cook D, Davis TZ, Stegelmeier BL (2018). Poisonous Plants of the United States (3th ed). Veterinary Toxicology, 837-889 (Chapter 61). 